\title{
Short communication: Feeding linseed oil to dairy goats with competent reticular groove reflex greatly increases $n-3$ fatty acids in milk fat
}

\author{
A. L. Martínez Marín, ${ }^{*}$ P. Gómez-Cortés,† D. Carrión Pardo,, N. Núñez Sánchez, ${ }^{*}$ G. Gómez Castro, ${ }^{*}$ \\ M. Juárez,† L. Pérez Alba, ${ }^{*}$ M. Pérez Hernández, ${ }^{*}$ and M. A. de la Fuente ${ }^{1}$ \\ *Departamento de Producción Animal (Universidad de Córdoba), Ctra. Madrid-Cádiz, s/n, Campus de Rabanales, 14071 Córdoba, Spain \\ †Instituto de Investigación en Ciencias de la Alimentación (CSIC-UAM), Nicolás Cabrera, 9. Universidad Autónoma de Madrid, 28049 Madrid, \\ Spain
}

\section{ABSTRACT}

A crossover experiment was designed to compare the effects of 2 ways of feeding linseed oil on milk fat fatty acid (FA) composition. Ten lactating goats, trained to keep competent their inborn reticular groove reflex, received a daily dose of linseed oil $(38 \mathrm{~g} / \mathrm{d})$ either with their solid (concentrate) feed (CON) or emulsified in skim milk and bottle-fed (BOT). Two groups of 5 goats received alternative and successively each of the treatments in two 15-d periods. $\alpha$-Linolenic acid in milk fat rose up to $13.7 \%$ in the BOT versus $1.34 \%$ in the $\mathrm{CON}$ treatment. The n-6 to n-3 FA ratio was significantly reduced in goats receiving bottle-fed linseed oil (1.49 vs. 0.49). Contents of rumen biohydrogenation intermediates of dietary unsaturated FA were high in milk fat of goats under the CON treatment but low in those in the BOT treatment. These results point to a clear rumen bypass of the bottle-fed linseed oil. This strategy allows obtaining milk fat naturally very rich in n-3 FA and very low in trans FA. Translating this approach into practical farm conditions could enable farmers to produce milk enriched in specific FA.

Key words: rumen bypass, goat milk, linseed oil, n-3 fatty acid

\section{Short Communication}

Milk fat consumption has been widely discouraged by nutritionists due to its high level of SFA and very low content of n-3 FA, which accounts for less than $1 \%$ of total FA (Jensen, 2002). However, recent research has demonstrated that n-3 FA in milk fat can be naturally increased by lipid supplementation in the dairy ruminant diet. The inclusion of linseed in the diet has been used to increase the $\alpha$-linolenic acid (ALA) contents in milk from cows (Loor et al., 2005), ewes (GómezCortés et al., 2009a), and goats (Martínez Marín et al.,

Received May 17, 2013.

Accepted August 25, 2013.

${ }^{1}$ Corresponding author: mafl@if.csic.es
2011), but, unfortunately, the final contents of ALA in milk were modest and seldom surpassed $2 \%$ of total FA. This result is attributable to the high rates of rumen biohydrogenation (BH) of ALA, reducing its absorption in the small intestine and consequently limiting its supply available to the mammary gland for incorporation into milk fat. The use of fat sources protected from rumen BH could be a more practical approach (Scott et al., 1971), but effective procedures of protection of unsaturated fats are proving elusive (Jenkins and Bridges, 2007).

Different researchers have shown interest in knowing the maximal proportions of different unsaturated long-chain FA that milk fat of ruminant species can accommodate. For that purpose, they have used animals cannulated in the abomasum or duodenum to infuse unsaturated FA mixtures past the rumen, avoiding their saturation. Using that procedure, Khas-Erdene et al. (2010) and Yang et al. (2012) increased the content and the yield, respectively, of $\alpha$-linolenic acid in cow milk fat more than 40 times the values found in noninfused animals. Obviously, this procedure cannot be translated into practical milk production.

Another experimental approach is to foster the reticular groove reflex (RGR) of the newborn ruminants into adulthood and use it to feed emulsified fat sources into the abomasum, bypassing the rumen. Ørskov (1982) highlighted such a possibility, which was used in ruminant lambs (Lawlor et al., 1971). Dobarganes García et al. (2005) used the RGR in adult lactating ewes with emulsified olive oil, showing that it was possible to bypass the rumen effectively according to the observed changes in milk fat FA composition. The aim of the present work was to compare the effects of feeding linseed oil, either mixed in the concentrate or bottle-fed, on milk fat FA composition of goats with competent RGR.

The experiment was carried out in the premises of the Animal Production building of the University of Córdoba (Córdoba, Spain), in accordance with the Spanish regulations on experimental animals. Ten primiparous goats of the Murciano-Granadina breed 
in their third month of lactation were used. They had competent RGR because they were brought up as described by Dobarganes García et al. (2005). Briefly, they were bottle-fed their dams' colostrum and milk up to $7 \mathrm{~d}$ old, and then bottle-fed milk replacer plus a solid diet. When the intake of solid feed was enough to wean them, the intake of bottle-fed reconstituted milk replacer ( $12 \%$ by weight) was lowered to $250 \mathrm{~mL} / \mathrm{d}$ and kept so during the rest of their lives, along with a normal solid diet. They were housed individually in $1.40-\mathrm{m}^{2}$ raised slatted floor cages with troughs for feed and water, in a temperature-controlled room (24 \pm $1^{\circ} \mathrm{C}$ ) lit for $16 \mathrm{~h}$ daily. Before the experiment, all the animals were vaccinated against contagious agalactia, gangrenous mastitis, Clostridium enterotoxemia, and hemorrhagic septicemia (Laboratorios Ovejero, León, Spain).

Two groups of 5 goats with competent RGR were used. Each group was allotted to 1 of 2 treatments: $38 \mathrm{~g}$ of linseed oil/d added to the concentrate part of the basal diet (CON treatment), or the same amount of linseed oil emulsified in skim milk and bottle-fed (BOT treatment). After a 15-d period, each treatment switched over to the other group and a new 15-d period ensued. The goats were machine milked and stripped out by hand daily before the morning feeding. Milk samples were taken on d 13, 14, and 15 of each period.

The diets had a solid and a liquid part (Table 1). The solid part of the diet was made of pelleted concentrate, alfalfa hay, and wheat straw. The liquid part of this diet was made of dry skim milk, soybean lecithin, and warm water. Linseed oil was given with the liquid part in the BOT treatment and with the solid part (included in the concentrate) in the CON treatment. Linseed oil used to supplement both diets consisted of $6.3 \% \mathrm{C} 16: 0,4.3 \%$ C18:0, 18.9\% cis-9 C18:1, 15.7\% cis-9,cis-12 C18:2, and 46.7\% ALA (Gustav Heess SL, Barcelona, Spain). Diets were fed in 2 meals at 0900 and $2000 \mathrm{~h}$. The liquid part of each diet was prepared just before feeding times as described by Dobarganes García et al. (2005).

Milk fats were extracted according to Luna et al. (2005) and FA methyl esters (FAME) were prepared by base-catalyzed methanolysis of the glycerides (ISOIDF, 2002a). Analysis of FAME was performed on a gas chromatograph with flame ionization detector (Agilent $6890 \mathrm{~N}$ Network System; Agilent Technologies Inc., Palo Alto, CA) onto a CP-Sil 88 fused silica capillary column $(100 \mathrm{~m} \times 0.25 \mathrm{~mm}$; Varian Inc., Middelburg, the Netherlands) under similar conditions to those reported by Luna et al. (2005). Individual FAME quantification was performed according to the International Organization for Standardization and International Dairy Federation (ISO-IDF, 2002b) using a milk fat with known composition (CRM 164; European
Community Bureau of Reference, Brussels, Belgium). Individual FA were identified by comparison with standards distributed by Nu-Chek Prep Inc. (Elysian, MN), whereas trans-11,cis-15 C18:2, trans-11,trans-15 C18:2, cis-9,trans-11,cis-15 C18:3, and cis-9,trans-11,trans- 15 C18:3 were previously identified by GC with a covalent adduct chemical ionization tandem mass spectrometry detector (Gómez-Cortés et al., 2009b).

Data were analyzed using PROC MIXED of SAS (version 9.1; SAS Institute Inc., Cary, NC) using period and treatment as fixed effects and the animal as random effect. Statistical significance was declared at $P<0.05$.

No differences were observed in milk production $(733$ and $758 \mathrm{~g} / \mathrm{d} ; \mathrm{SEM}=76.2)$ or milk fat content (5.01 and $5.11 \%$; SEM $=0.204$ ) between the CON and BOT treatments, respectively. Results of milk fat FA composition obtained from treatment CON and BOT are shown in Table 2. To compare these results, we included the FA profile of a reference goat milk fat (RGMF) obtained with 4 basal diets similar to the solid part of the diets used in the present experiment but without added oil (Martínez Marín et al., 2011, 2012; Table 2). The levels of cis-9,cis-12 C18:2 and cis-9,cis-12,cis-15 C18:3, both of them necessarily of direct dietary origin, were 3 and 10 times, respectively, higher in milk from the BOT treatment than in milk from the CON treatment. These results would support the effectiveness of the RGR to bypass the rumen with liquid feed in adult animals.

The content of ALA in milk fat of goats fed the BOT treatment was 85 times higher than the average content of this FA in the RGMF (Table 2). The ALA content in the milk fat of BOT goats in the present experiment

Table 1. Experimental diets

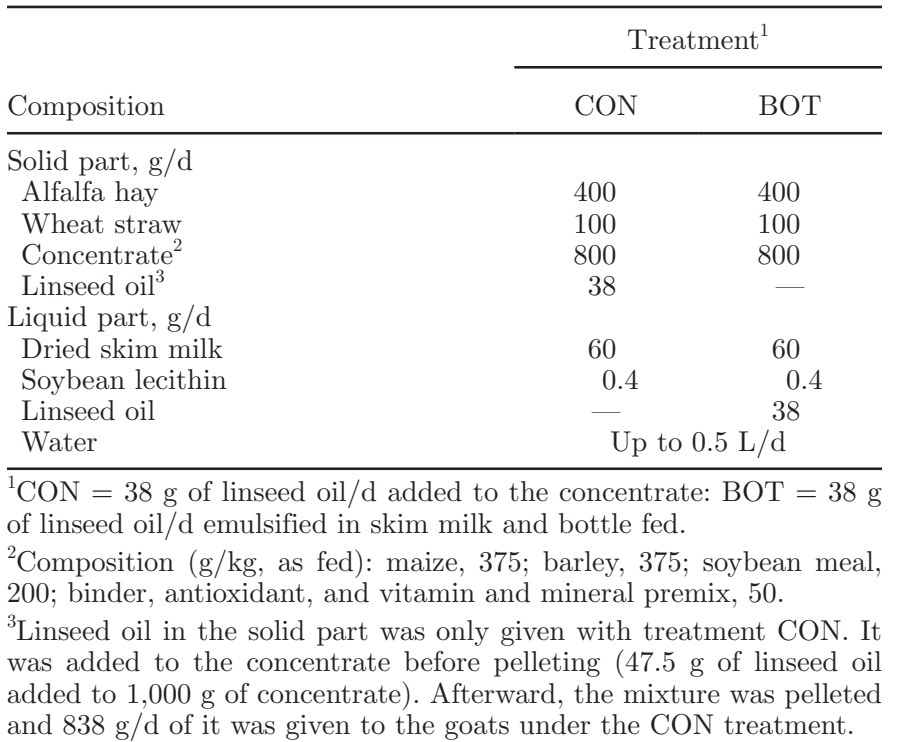


Table 2. Milk FA profile ( $\mathrm{g} / 100 \mathrm{~g}$ of FA methyl esters) in goats with competent reticular groove reflex receiving $38 \mathrm{~g}$ of linseed oil/d either in the concentrate $(\mathrm{CON})$ or emulsified in skim milk and bottle fed (BOT)

\begin{tabular}{|c|c|c|c|c|c|}
\hline \multirow[b]{2}{*}{$\mathrm{FA}$} & \multicolumn{2}{|c|}{ Treatment } & \multirow[b]{2}{*}{ SEM } & \multirow[b]{2}{*}{$P$-value } & \multirow[b]{2}{*}{$\mathrm{RGMF}^{1}$} \\
\hline & $\mathrm{CON}$ & BOT & & & \\
\hline \multicolumn{6}{|l|}{ SFA } \\
\hline $\mathrm{C} 4: 0$ & 2.61 & 2.01 & 0.097 & $<0.001$ & $2.47 \pm 0.040$ \\
\hline C6:0 & 3.00 & 2.45 & 0.101 & 0.001 & $2.76 \pm 0.054$ \\
\hline $\mathrm{C} 8: 0$ & 3.29 & 2.78 & 0.109 & 0.005 & $3.03 \pm 0.078$ \\
\hline C10:0 & 10.33 & 9.72 & 0.318 & 0.19 & $11.33 \pm 0.20$ \\
\hline $\mathrm{C} 12: 0$ & 4.31 & 4.82 & 0.199 & 0.066 & $5.22 \pm 0.194$ \\
\hline iso C13:0 & 0.02 & 0.01 & 0.001 & 0.001 & $0.02 \pm 0.002$ \\
\hline anteiso $\mathrm{C} 13: 0$ & 0.05 & 0.06 & 0.005 & 0.88 & $0.06 \pm 0.006$ \\
\hline iso C14:0 & 0.09 & 0.10 & 0.018 & 0.90 & $0.05 \pm 0.002$ \\
\hline C14:0 & 7.10 & 7.05 & 0.209 & 0.89 & $10.39 \pm 0.18$ \\
\hline iso $\mathrm{C} 15: 0$ & 0.17 & 0.13 & 0.010 & 0.037 & $0.14 \pm 0.004$ \\
\hline anteiso $\mathrm{C} 15: 0$ & 0.29 & 0.17 & 0.018 & $<0.001$ & $0.28 \pm 0.011$ \\
\hline C15:0 & 0.80 & 0.59 & 0.044 & 0.019 & $0.83 \pm 0.047$ \\
\hline iso C16:0 & 0.19 & 0.14 & 0.016 & 0.045 & $0.15 \pm 0.007$ \\
\hline C16:0 & 20.60 & 18.86 & 0.657 & 0.041 & $32.56 \pm 0.58$ \\
\hline $\mathrm{C} 17: 0$ & 0.38 & 0.32 & 0.020 & 0.12 & $0.40 \pm 0.011$ \\
\hline iso C18:0 & 0.05 & 0.04 & 0.003 & 0.21 & $0.04 \pm 0.003$ \\
\hline 10-keto C18:0 & 0.17 & 0.03 & 0.557 & 0.004 & $0.04 \pm 0.004$ \\
\hline C18:0 & 8.32 & 4.92 & 0.014 & 0.001 & $5.78 \pm 0.253$ \\
\hline $\mathrm{C} 20: 0$ & 0.16 & 0.13 & 0.002 & 0.19 & $0.11 \pm 0.004$ \\
\hline \multicolumn{6}{|l|}{ MUFA } \\
\hline cis-9 C10:1 & 0.41 & 0.39 & 0.027 & 0.62 & $0.39 \pm 0.027$ \\
\hline cis-9 C12:1/C13:0 & 0.23 & 0.22 & 0.018 & 0.84 & $0.22 \pm 0.020$ \\
\hline cis-9 C14:1 & 0.14 & 0.12 & 0.010 & 0.33 & $0.22 \pm 0.021$ \\
\hline cis-9 C15:1 & 0.05 & 0.03 & 0.003 & 0.003 & $0.05 \pm 0.003$ \\
\hline trans-9 C16:1/iso C17:0 & 0.61 & 0.18 & 0.060 & $<0.001$ & $0.34 \pm 0.014$ \\
\hline cis-7 C16:1 & 0.28 & 0.18 & 0.017 & 0.001 & $0.24 \pm 0.007$ \\
\hline cis-9 C16:1/anteiso C17:0 & 0.91 & 0.70 & 0.042 & 0.001 & $1.32 \pm 0.065$ \\
\hline cis-13 C16:1 & 0.18 & 0.21 & 0.016 & 0.22 & $0.28 \pm 0.022$ \\
\hline cis-9 C17:1 & 0.17 & 0.15 & 0.016 & 0.35 & $0.21 \pm 0.009$ \\
\hline trans-6/trans- $7 /$ trans-8 C18:1 & 0.27 & 0.05 & 0.030 & $<0.001$ & $0.17 \pm 0.010$ \\
\hline trans-9 C18:1 & 0.34 & 0.07 & 0.036 & $<0.001$ & $0.19 \pm 0.009$ \\
\hline trans-10 C18:1 & 0.51 & 0.12 & 0.077 & 0.016 & $0.33 \pm 0.034$ \\
\hline trans-11 C18:1 & 3.65 & 0.23 & 0.495 & $<0.001$ & $1.01 \pm 0.087$ \\
\hline trans-12 C18:1 & 0.38 & 0.07 & 0.039 & $<0.001$ & $0.18 \pm 0.011$ \\
\hline cis-9 C18:1 & 17.45 & 18.15 & 0.659 & 0.59 & $14.55 \pm 0.34$ \\
\hline trans-15/cis-11 C18:1 & 0.62 & 0.31 & 0.043 & $<0.001$ & $0.31 \pm 0.013$ \\
\hline cis-12 C18:1 & 0.74 & 0.10 & 0.091 & $<0.001$ & $0.14 \pm 0.010$ \\
\hline cis-13 C18:1 & 0.08 & 0.02 & 0.008 & $<0.001$ & $0.04 \pm 0.002$ \\
\hline trans-16/cis-14 C18:1 & 0.51 & 0.09 & 0.050 & $<0.001$ & $0.18 \pm 0.007$ \\
\hline cis-15 C18:1 & 0.52 & 0.04 & 0.059 & $<0.001$ & $0.06 \pm 0.002$ \\
\hline cis-11 C20:1 & 0.09 & 0.07 & 0.005 & 0.066 & $0.05 \pm 0.002$ \\
\hline \multicolumn{6}{|l|}{ Nonconjugated C18:2 } \\
\hline trans-11,trans-15 C18:2 & 0.12 & 0.03 & 0.016 & 0.001 & $0.04 \pm 0.003$ \\
\hline trans-9,trans-12/cis-9,trans-13/trans- 8, cis-12 C18:2 & 0.57 & 0.10 & 0.062 & $<0.001$ & $0.17 \pm 0.007$ \\
\hline trans-8, cis-13 18:2/cis-9,trans-12 C18:2 & 0.33 & 0.11 & 0.030 & $<0.001$ & $0.06 \pm 0.002$ \\
\hline trans-11,cis-15 C18:2 & 1.40 & 0.04 & 0.193 & $<0.001$ & $0.04 \pm 0.002$ \\
\hline cis-9,cis-12 C18:2 & 2.22 & 6.54 & 0.512 & $<0.001$ & $1.72 \pm 0.055$ \\
\hline \multicolumn{6}{|l|}{ Conjugated C18:2 } \\
\hline cis-9,trans-11 C18:2 & 2.10 & 0.23 & 0.290 & 0.001 & $0.62 \pm 0.050$ \\
\hline trans -9, cis-11 C18:2 & 0.02 & 0.01 & 0.002 & 0.005 & $0.01 \pm 0.001$ \\
\hline trans-11,cis-13 C18:2 & 0.02 & $\operatorname{Tr}^{2}$ & 0.004 & 0.010 & $0.01 \pm 0.001$ \\
\hline trans-11,trans-13 C18:2 & 0.02 & 0.01 & 0.002 & 0.13 & $0.01 \pm 0.001$ \\
\hline trans- 9, trans-11 C18:2 & 0.03 & 0.01 & 0.003 & 0.023 & $0.01 \pm 0.001$ \\
\hline \multicolumn{6}{|l|}{ Other PUFA } \\
\hline C16:2 & 0.08 & $\operatorname{Tr}$ & 0.010 & $<0.001$ & $0.01 \pm 0.001$ \\
\hline cis-9,cis-12,cis-15 C18:3 & 1.34 & 13.67 & 1.465 & $<0.001$ & $0.16 \pm 0.008$ \\
\hline cis-9,trans-11,trans-15 C18:3 & 0.09 & 0.01 & 0.013 & 0.001 & $0.01 \pm 0.001$ \\
\hline cis-9,trans-11,cis-15 C18:3 & 0.13 & 0.03 & 0.022 & 0.023 & $0.04 \pm 0.002$ \\
\hline $\mathrm{C} 20: 3 \mathrm{n}-3$ & 0.02 & 0.07 & 0.008 & $<0.001$ & $0.01 \pm 0.001$ \\
\hline $\mathrm{C} 20: 4 \mathrm{n}-6$ & 0.20 & 0.14 & 0.020 & 0.11 & $0.14 \pm 0.005$ \\
\hline C20:5n-3 & 0.07 & 0.16 & 0.013 & $<0.001$ & $0.02 \pm 0.001$ \\
\hline
\end{tabular}


Table 2 (Continued). Milk FA profile (g/100 g of FA methyl esters) in goats with competent reticular groove reflex receiving $38 \mathrm{~g}$ of linseed oil/d either in the concentrate $(\mathrm{CON})$ or emulsified in skim milk and bottle fed $(\mathrm{BOT})$

\begin{tabular}{lrrrrrr}
\hline & \multicolumn{2}{c}{ Treatment } & & & \\
\cline { 2 - 3 } FA & CON & BOT & & SEM & P-value & RGMF $^{1}$ \\
\hline C22:5n-3 & 0.12 & 0.11 & 0.009 & 0.47 & $0.04 \pm 0.002$ \\
n-6:n-3 & 1.49 & 0.49 & 0.132 & $<0.001$ & $8.15 \pm 0.305$ \\
Total SFA & 61.97 & 54.38 & 1.404 & $<0.001$ & $76.09 \pm 0.431$ \\
Total MUFA & 28.13 & 21.51 & & 0.989 & $<0.001$ & $20.57 \pm 0.391$ \\
Total PUFA & 9.42 & 23.21 & 1.711 & $<0.001$ & $3.33 \pm 0.093$ \\
Total trans FA $^{3}$ & 9.31 & 1.40 & 1.051 & $<0.001$ & $3.01 \pm 0.162$ \\
\hline
\end{tabular}

${ }^{1}$ Fatty acid profile of reference goat milk fat (RGMF); mean values of milk obtained with 4 control, no oiladded diets from Martínez Marín et al. (2011, 2012). The values are means \pm SEM.

${ }^{2} \mathrm{Tr}=$ concentrations below $0.01 \mathrm{mg} / 100 \mathrm{~g}$ of FA methyl esters.

${ }^{3}$ Includes the sum of all trans MUFA plus all nonconjugated C18:2 with at least a trans bond.

accounted for $13.7 \%$ of total FAME. To our knowledge, no other experiment on the effects of supplementing RGR-competent dairy ruminants with PUFA-rich fats has been published. However, published infusion experiments could be useful to compare these results. Khas-Erdene et al. (2010) used continuous duodenal infusions of emulsified ALA-rich FA mixtures, reporting very high ALA content in milk fat (25.4\%) with daily doses of $132 \mathrm{~g}$ of ALA. Moallem et al. (2012) also infused dairy cows 0 (control treatment), 110, or 220 $\mathrm{g}$ of linseed oil/d into the abomasum in 2 equal doses. The resulting values in ALA content in milk fat were 9 and 16 times, respectively, higher than the value of the control treatment.

Results of contents in the milk fat of FA originated in the rumen by $\mathrm{BH}$ of dietary FA indicated that the BOT treatment had consistently and significantly lower values than the CON treatment (Table 2). Accordingly, trans-11,trans-15 C18:2, cis-9,trans-11,cis-15 C18:3, and cis-9,trans-11,trans-15 C18:3, previously identified as intermediates of the BH of ALA (Gómez-Cortés et al., 2009b), were found in very low amounts in the BOT treatment. Furthermore, milk from the BOT treatment presented a significant reduction of all trans FA (Table 2 ) isomers, confirming an effective rumen bypass of the linseed oil when bottle-fed to goats. Comparing the contents of FA originated in rumen metabolism (most unsaturated FA) in the BOT and RGMF treatments (Table 2), the effectiveness of the RGR for bypassing the rumen in adult animals was strongly supported.

Short-chain FA (C4:0, C6:0, and C8:0), C16:0, and C18:0 all decreased with the BOT compared with the CON treatment (Table 2), whereas medium-chain SFA were not different between treatments (C10:0, $\mathrm{C} 12: 0$, and $\mathrm{C} 14: 0)$. The low levels of $\mathrm{C} 18: 0$ in BOT milk fat (half of the CON treatment) supports again the efficiency of the bypass in RGR-competent animals because this FA is the $\mathrm{BH}$ final product of ALA in the rumen. The decrement of short-chain FA in milk fat was already reported in response to increasing amounts of ALA infused into the duodenum of lactating cows (Khas-Erdene et al., 2010) and could be related to changes of the lipogenic gene network in the mammary epithelial cells due to the increased supply of long-chain FA to the mammary gland (LaCount et al., 1994). The FA synthesized by the mammary gland decreased with mammary uptake of ALA after its duodenal infusion (Yang et al., 2012), which suggests an inhibition of FA synthesis when the amount of ALA taken up by the mammary gland increased. Barbano and Sherbon (1980) hypothesized that a large diglyceride pool of high molecular weight resulting from incorporation of exogenous long-chain FA taken up in the plasma might result in a larger output of $\mathrm{C} 4: 0$ to maintain fluidity of milk fat at body temperature. Such a compensatory effect was confirmed more important with C16:0 and C18:0 than with cis-9 C18:1, which has a low melting point, similar to short-chain FA (Enjalbert et al., 1998). As ALA has an even lower melting point than cis-9 C18:1, biosynthesis of short-chain FA likely did not need to be enhanced when ALA was infused into the duodenum. On the contrary, a negative correlation trend between ALA mammary gland uptake and balance of C4:0 was observed (Yang et al., 2012).

Concerning C16:0, its lower level in treatment BOT was in accordance with results of Khas-Erdene et al. (2010), who reported increasing amounts of ALA when infused duodenally. Furthermore, strong negative correlations between ALA and C16:0 have been documented in cow milk fat generated after infusion of flaxseed oil (Moallem et al., 2012) and ALA (Yang et al., 2012) in the digestive tract. Moallem et al. (2012) attributed this decrease to replacement of the portion derived from the circulating C16:0 source (dietary and mobilized) by ALA, but Yang et al. (2012) confirmed a lower synthesis of C16:0 when higher amounts of ALA were taken up 
by the mammary gland. Although the decrease in the short-chain FA content in RGR-competent goat milk fat (Table 2) suggests that the decrease in C16:0 would be caused by a suppression of de novo FA synthesis, more research would be needed to clarify this point.

Apart from infusion experiments in the digestive tract, the percentage of n-3 FA measured in milk fat from goats in the BOT treatment is the greatest reported by a large margin in dairy ruminants. According to the European Union Regulations (European Union, 2006 , 2010) this milk may qualify as food enriched in n-3 FA. Even more, consumption of this milk may greatly contribute to diminish the $\mathrm{n}-6: \mathrm{n}-3$ ratio and the total trans FA content compared with milk from the CON treatment (Table 2), which could add to its healthy properties (Lock and Bauman, 2004; Simopoulos, 2008).

In conclusion, using intact, healthy, RGR-competent dairy goats allowed us to produce milk rich in ALA. Other FA could be fed that way to obtain milk rich in, for example, eicosapentaenoic acid and docosahexaenoic acid, among other FA. The possibility of using the RGR in the farm to produce milk naturally enriched in chosen unsaturated FA arises from the results of this work. More research efforts should be made to verify this possibility.

\section{ACKNOWLEDGMENTS}

This work was financed by the Ministerio de Ciencia e Innovación (MICINN, Madrid, Spain; AGL2008-04805 and Consolider Ingenio 2010 Programme; FUN-CFOOD CSD2007-063) and the Comunidad Autónoma de Madrid (Spain; 2009-AGR-1469). The authors thank A. Jiménez Secilla and B. Garfia Catalán of Laboratorio Agropecuario Regional of Córdoba (Spain) for their help with milk composition analysis. Thanks to I. Andújar-Ramírez (Universidad de Córdoba, Córdoba, Spain) and M. V. Rodríguez-Pino (CSIC, Madrid, Spain) for their technical assistance in processing milk samples and J. J. Pérez-Hernández (Universidad de Córdoba, Córdoba, Spain) for his assistance in animal feeding and management.

\section{REFERENCES}

Barbano, D. M., and J. W. Sherbon. 1980. Polyunsaturated protected lipid: Effect on triglyceride molecular weight distribution. J. Dairy Sci. 63:731-740.

Dobarganes García, C., M. Pérez Hernández, G. Cantalapiedra, J. M. Salas, and J. A. Merino. 2005. Bypassing the rumen in dairy ewes: The reticular groove reflex vs. calcium soap of olive fatty acids. J. Dairy Sci. 88:741-747.

Enjalbert, F., M. Nicot, C. Bayourthe, and R. Moncoulon. 1998. Duodenal infusions of palmitic, stearic, or oleic acids differently affect mammary gland metabolism of fatty acids in lactating dairy cows J. Nutr. 128:1525-1532.

European Union. 2006. Regulation (EC) No. 1924/2006 of the European Parliament and of the Council of 20 December 2006 on nutrition and health claims made on foods. Official J. Eur. Union, L 404:9-25.

European Union. 2010. Amending Regulation (EC) No. 1924/2006 of the European Parliament and of the Council with regard to the list of nutrition claims. Commission Regulation (EU) No. 116/2010 of 10 February 2010. Official J. Eur. Union, L 37:16-19.

Gómez-Cortés, P. A. Bach, P. Luna, M. Juárez, and M. A. de la Fuente. 2009a. Effects of extruded linseed supplementation on n-3 fatty acids and conjugated linoleic acid in milk and cheese from ewes. J. Dairy Sci. 92:4122-4134.

Gómez-Cortés, P., C. Tyburczy, J. T. Brenna, M. Juárez, and M. A. de la Fuente. 2009b. Characterization of cis-9 trans-11 trans-15 C18:3 in milk fat by GC and covalent adduct chemical ionization tandem MS. J. Lipid Res. 50:2412-2420.

ISO-IDF (International Organization for Standardization-International Dairy Federation). 2002a. Milk fat-Preparation of fatty acid methyl esters. International Standard ISO 15884:2002-IDF 182:2002. IDF, Brussels, Belgium.

ISO-IDF (International Organization for Standardization-International Dairy Federation). 2002b. Milk fat-Determination of the fatty acid composition by gas-liquid chromatography. International Standard ISO 15885:2002-IDF 184: 2002. IDF, Brussels, Belgium.

Jenkins, T. C., and W. C. Bridges Jr. 2007. Protection of fatty acids against ruminal biohydrogenation in cattle. Eur. J. Lipid Sci. Technol. 109:778-789.

Jensen, R. G. 2002. The composition of bovine milk lipids: January 1995 to December 2000. J. Dairy Sci. 85:295-350.

Khas-Erdene, J. Q. Wang, D. P. Bu, L. Wang, J. K. Drackley, Q. S. Liu, G. Yang, H. Y. Wei, and L. Y. Zhou. 2010. Responses to increasing amounts of free alpha-linolenic acid infused into the duodenum of lactating dairy cows. J. Dairy Sci. 93:1677-1684.

LaCount, D. W., J. K. Drackley, S. O. Laesch, and J. H. Clark. 1994. Secretion of oleic acid in milk fat in response to abomasal infusions of canola or high oleic sunflower fatty acids. J. Dairy Sci. 77:1372-1385

Lawlor, M. J., S. P. Hopkins, and J. K. Kealy. 1971. The functioning of the oesophageal groove reflex and comparison of the performance of lambs fed individually or in groups. Br. J. Nutr. 26:439-448.

Lock, A. L., and D. E. Bauman. 2004. Modifying milk fat composition of dairy cows to enhance fatty acids beneficial to human health. Lipids 39:1197-1206.

Loor, J. J., A. Ferlay, A. Ollier, K. Ueda, M. Doreau, and Y. Chilliard. 2005. High-concentrate diets and polyunsaturated oils alter trans and conjugated isomers in bovine rumen, blood, and milk. J. Dairy Sci. 88:3986-3999.

Luna, P., J. Fontecha, M. Juárez, and M. A. de la Fuente. 2005. Changes in the milk and cheese fat composition of ewes fed commercial supplements containing linseed with special reference to the CLA content and isomer composition. Lipids 40:445-454.

Martínez Marín, A. L., P. Gómez-Cortés, A. G. Gómez Castro, M. Júarez, L. M. Pérez Alba, M. Pérez Hernández, and M. A. de la Fuente. 2011. Animal performance and milk fatty acid profile of dairy goats fed diets with different unsaturated plant oils. J. Dairy Sci. 94:5359-5368

Martínez Marín, A. L., P. Gómez-Cortés, G. Gómez Castro, M. Juárez, L. Pérez Alba, M. Pérez Hernández, and M. A. de la Fuente. 2012. Effects of feeding increasing dietary levels of high oleic or regular sunflower or linseed oil on fatty acid profile of goat milk. J. Dairy Sci. 95:1942-1955.

Moallem, U., D. Vyas, B. B. Teter, P. Delmonte, M. Zachut, and R. A. Erdman. 2012. Transfer rate of $\alpha$-linolenic acid from abomasally infused flaxseed oil into milk fat and the effects on milk fatty acid composition in dairy cows. J. Dairy Sci. 95:5276-5284.

Ørskov, E. R. 1982. Protein Nutrition in Ruminants. Academic Press, London, UK. 
Scott, T. W., L. J. Cook, and S. C. Mills. 1971. Protection of dietary polyunsaturated fatty acids against microbial hydrogenation in ruminants. J. Am. Oil Chem. Soc. 48:358-364.

Simopoulos, A. P. 2008. The importance of the omega-6/omega-3 fatty acid ratio in cardiovascular disease and other chronic diseases. Exp. Biol. Med. 233:674-688.
Yang, G., D. P. Bu, J. Q. Wang, Khas-Erdene, L. Y. Zhou, and J. J. Loor. 2012. Duodenal infusion of $\alpha$-linolenic acid affects fatty acid metabolism in the mammary gland of lactating dairy cows. J. Dairy Sci. 95:5821-5830. 